\title{
Stress-Optimised Shape Memory Devices for the Use in Microvalves
}

\author{
K.D. Skrobanek, M. Kohl and S. Miyazaki* \\ Forschungszentrum Karlsruhe GmbH, IMT, Postfach 3640, 76021 Karlsruhe, Germany \\ * University of Tsukuba, Institute of Materials Science, Tsukuba, Ibaraki 305, Japan
}

\begin{abstract}
A gas valve of $6 \times 6 \times 2 \mathrm{~mm}^{3}$ size has been developed for high pressure applications. Stress-optimised shape memory microbeams of $100 \mu \mathrm{m}$ thickness are used to control the deflection of a membrane above a valve chamber. The shape memory thin sheets have been fabricated by melting and rolling, which creates specific textures. Investigations by X-ray diffraction revealed major orientations of [111] and [011] in rolling direction. The corresponding maximum anisotropy of transformation strain was $20 \%$. The microbeams have been fabricated by laser cutting. For stress-optimisation, the lateral widths of the beams are designed for homogeneous stress distributions along the beam surfaces allowing an optimised use of the shape memory effect and a minimisation of fatigue effects. For actuation, a rhombohedral phase transformation is used. This allows operation below pressure differences of $1200 \mathrm{hPa}$ in designs with one valve chamber and below $4500 \mathrm{hPa}$ in pressure-compensated designs with a second valve chamber above the membrane. Maximum gas flows of $1600 \mathrm{sccm}\left(\mathrm{sccm}=\mathrm{cm}^{2}\right.$ at standart conditions / minute) and work outputs of $35 \mu \mathrm{Nm}$ are achieved for a driving power of $210 \mathrm{~mW}$. The response times for closing the valves vary between 0.5 and $1.2 \mathrm{~s}$ and for opening between 1 and $2 \mathrm{~s}$ depending on the applied pressure difference.
\end{abstract}

\section{INTRODUCTION}

Currently, microactuators based on shape memory alloys (SMA) are being developed, which are characterised by high forces and displacements in restricted space. The base material for these actuators are SMA thin films produced by sputter deposition [1-8] or SMA thin sheets fabricated by melting and subsequent rolling [9-14]. By rolling, device thicknesses above about $30 \mu \mathrm{m}$ can be obtained, which are particularly interesting in terms of work outputs and power consumption. Since rolling creates specific textures causing anisotropic physical properties $[15,16]$, it is important to evaluate these effects.

For micromachining of SMA thin sheets, the methods of laser cutting and electrolytic photoetching have been optimised, allowing the realisation of lateral dimensions of a few tens of microns. An optimum use of the shape memory effect requires specific designs, with homogeneous spatial stress profiles for a given load pattern. The stress values should be sufficiently high to provide large work outputs, but low enough to avoid fatigue effects [17]. Both contradictory requirements have been taken into account in a design of a stress-optimised TiNi microdevice of $100 \mu \mathrm{m}$ thickness for actuation of membrane microvalves.

In order to evaluate the effect of rolling on the shape memory behavior of $100 \mu \mathrm{m}$ thick TiNi sheets, the texture and the resulting anisotropy of transformation strains are investigated. Thermal measurements are performed to determine temperature distributions along the surface of the microfabricated TiNi devices during actuation. Further experiments concentrate on quasi-static and time-resolved mechanical and electrical properties of two types of microvalves fabricated from the TiNi microdevices.

\section{PHYSICAL PROPERTIES OF THE SPECIMENS}

Thin sheets of $\mathrm{Ti}-50$ at $\% \mathrm{Ni}$ have been made by melting $\mathrm{Ti}$ and $\mathrm{Ni}$ in a high frequency induction furnace followed by final cold-rolling with $20 \%$ reduction. The final thickness of the thin sheets was $100 \mu \mathrm{m}$. Tensile specimens have been spark-cut from the thin sheets parallel and perpendicular to the rolling direction (RD). Another specimen has been prepared for a texture analysis by the X-ray diffraction method. Oxide layers have been removed by chemical and mechanical polishing, the surfaces have been finished by electropolishing.

The sheets have been heat-treated at $530^{\circ} \mathrm{C}$ for $3.6 \mathrm{ks}$ in vacuum with subsequent cooling in gaseous nitrogen to adjust the one-way-effect. In differential scanning calorimetry measurements, a two-stage transformation from the austenitic (B2)-phase to rhombohedral (R)-phase to a martensitic (M)-phase is observed upon cooling. Upon heating, a single-stage transformation from $\mathrm{M}$ to $\mathrm{B} 2$ occurs. The 
corresponding start and finish temperatures of the transformation $\mathrm{Ms}, \mathrm{Mf}, \mathrm{Rs}, \mathrm{Rf}$, As and Af are $23^{\circ} \mathrm{C}$, $10^{\circ} \mathrm{C}, 44^{\circ} \mathrm{C}, 38^{\circ} \mathrm{C}, 54^{\circ} \mathrm{C}$ and $66^{\circ} \mathrm{C}$, respectively.

The rolling-induced texture has been investigated by $\mathrm{X}$-ray diffraction measurements. Fig. 1 shows three pole figures at room temperature presenting the orientation distribution of the $\mathrm{X}$-ray diffraction intensity reflected from the $\{110\},\{100\}$ and $\{211\}$ planes, respectively. The vertical and horizontal axes denote the rolling direction (RD) and transverse direction (TD), respectively. In Fig. 1(a), the normalised intensity concentrates both at the center of the pole figure and $R D$, while the intensity is weak and uniformly distributed at TD revealing a major orientation [011] along RD. Another major orientation is [111] as determined from the orientation distribution function.

The influence of the texture on the mechanical properties has been investigated by thermally cycled tensile tests under constant loads. The tensile axis were parallel to RD and TD. From these measurements, the recovery strain $\varepsilon_{\mathrm{A}}$ and plastic strain $\varepsilon_{\mathrm{p}}$ have been determined as a function of stress as shown in Fig. 2. The recovery strain $\varepsilon_{\mathrm{A}}$ is associated with the complete reverse transformation from $\mathbf{M}$ - to B2-phase, $\varepsilon_{\mathrm{p}}$ is due to slip deformation induced during the proceding transformations. $\varepsilon_{\mathrm{A}}$ increases with increasing stress and reaches maximum values of about $5 \%$ for RD and $4.1 \%$ for TD, which corresponds to a maximum anisotropy of transformation strain of $20 \%$. The larger transformation strains for RD compared to TD are due to the major axes [011] and [111] in RD. In TD, no specific major orientation exists resulting in lower values for recovery and plastic strains. The critical stress for slip deformation is higher for TD compared to $\mathrm{RD}$, namely about $90 \mathrm{MPa}$ and $60 \mathrm{MPa}$, respectively.

For actuation, the SMA devices are driven by direct electrical heating. Fig. 3 shows a temperatureresistance characteristic of a double-beam test device determined for zero external load by the four-point method. The measurements have been performed in thermal equilibrium by step-wise ramping the external temperature with sufficient waiting time. The plot reveals the typical features also observed in bulk materials[18]. Since during actuation the device temperature is cycled above room temperature, only the R-phase transformation is used.

\section{Ti-50.0at\%Ni \\ Cold-rolled plate $\mathrm{Ta}=773 \mathrm{~K}$}

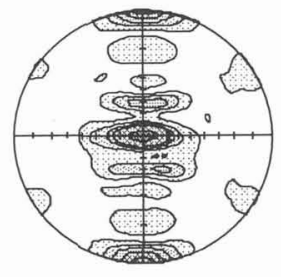

$\{110\}$ pole figure

a)

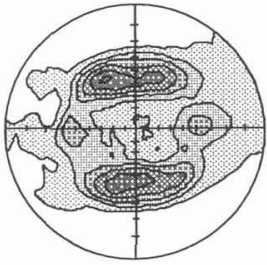

$\{100\}$ pole figure

b)

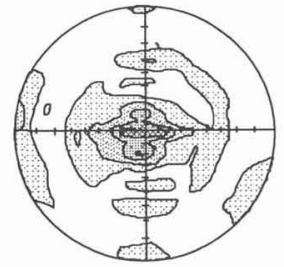

$5.00-5.50$

$4.50-5.00$

$350-400$

$3.00-3.50$

$2.50-3.00$

.00-2.50

$1.00-1.50$

$0.50-1.00$

$0.00-0.50$

$\{211\}$ pole figure

c)

Figure 1: Three perfect pole figures, which show the orientation distribution of the X-ray diffraction intensity.

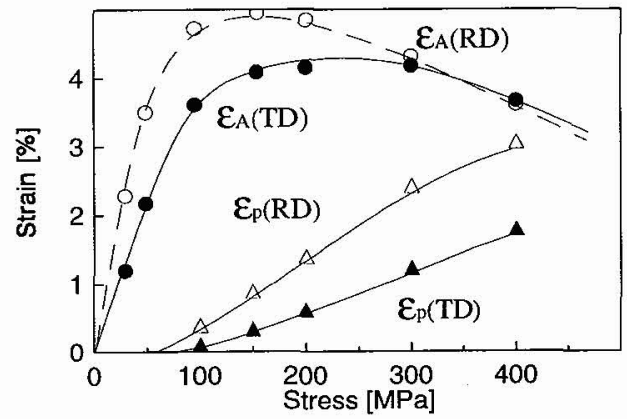

Figure 2: Recovery strain $\varepsilon_{\mathrm{A}}$ and plastic strain $\varepsilon_{\mathrm{p}}$ as a function of stress, for tensile axes along rolling direction (RD) and transverse direction (TD).

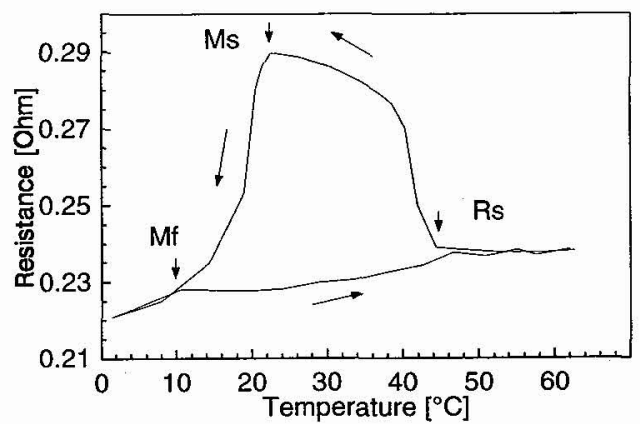

Figure 3: Resistance-temperature characteristic of a complete martensitic transformation. The transformation temperatures are indicated. 


\section{DESIGN AND FABRICATION OF THE MICROVALVES}

The operation principle of the microvalves is based on the use of a SMA microdevice for deflection control of a membrane, which thus opens or closes a valve port. The valve is designed for operation in a normally open condition, where a pressure difference acts as a biasing force against the actuation force generated by the SMA device. A cross-section of the microvalve is shown in Fig. 4.

A PMMA (polymethylmetacrylat) substrate has been processed by mechanical micromachining to establish a pressure chamber with inlet and outlet ports $A$ and $B$. The diameter of the pressure chamber was $4 \mathrm{~mm}$. The inner and outer diameter of the valve seat were 0.5 and $1 \mathrm{~mm}$, respectively. Lateron, a high flexible polyimide membrane of $3 \mu \mathrm{m}$ thickness has been bonded to the substrate. Brass contact pins have been connected to the substrate by adhesive bonding. A SMA device consisting of a circular array of double-beam bending elements has been manufactured by laser cutting and, subsequently, integrated onto the membrane by adhesive bonding. Between membrane and SMA device, a spacer has been integrated to adjust the constraint force, which the SMA device exerts on the valve seat. Finally, a PMMA cover with port $\mathrm{C}$ has been mounted on top for use as a second pressure chamber allowing to compensate the pressure on the membrane by a fluidic short-cut. An assembled microvalve without PMMA cover is shown in Fig. 5.

For improvement of the work output, the SMA microdevice has been stress-optimised [10,12]. The basic idea of stress optimisation is to design the beams of the SMA device in such a way that spatially homogeneous stress profiles are obtained for a given load pattern. Optimisation of each beam has been performed by using the width of the beam $w(x)$ as a variable dimension in beam direction $x$. The maximum stress $\sigma \mathrm{s}(\mathrm{x})$ along the surface of the SMA device is given by the bending-moment $M_{y}(x)$, the moment of inertia $I_{y}(x)$ and the distance between the surface and the neutral fiber $h / 2$ :

$$
\sigma s(x)=\frac{M y(x)}{I y(x)} \cdot \frac{h}{2}
$$

with $I_{y}(x)=\left(w(x) h^{3}\right) / 12$ for rectangular cross-sections. The bending moment is given by the pressure difference acting on the membrane and geometric parameters. Stress-optimised designs are characterised by a constant stress profile along the surface. The maximum stress should be sufficiently high to obtain high work outputs, but below the critical stress for plastic deformation $\sigma_{\mathrm{s}}(\mathrm{x})=\sigma_{\text {imit }}<\sigma_{p}$. From this condition, equation (1) allows the determination of an analytical expression for the corresponding width profile $w(x)$ of the beams:

$$
w(x)=\frac{6 \cdot M y(x)}{\operatorname{Gimit} \cdot h^{2}}
$$

In the specimens, $\sigma_{p}$ is about $60 \mathrm{MPa}$ in $\mathrm{RD}$. Taking into account a given membrane radius of $2 \mathrm{~mm}$ and limits for the minimum and maximum beam widths of 100 and $550 \mu \mathrm{m}$, respectively, a final device geometry with eight stress-optimised double-beams has been designed as shown in the inset of Fig. 5 . The operation of the valves has been investigated in three modes as illustrated in Fig. 6 . In operation mode (a), ports $\mathrm{A}$ and $\mathrm{B}$ are connected to the inlet pressure to obtain a membrane actuator for characterisation of the force-deflection behavior of the microdevice-membrane composite. In valve actuation mode (b), the inlet pressure is applied to port B, while port A remains open. In valve actuation mode (c), port $\mathrm{A}$ is interconnected to port $\mathrm{C}$ of a second pressure chamber on top to partially compensate the effect of pressure on the membrane.

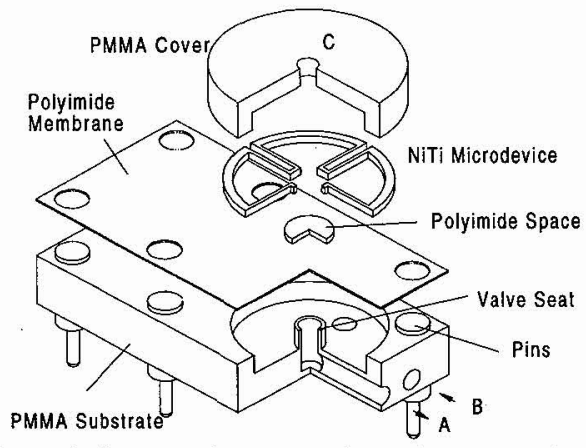

Figure 4: Cross-section of the microvalve. A, B and C denote valve ports.

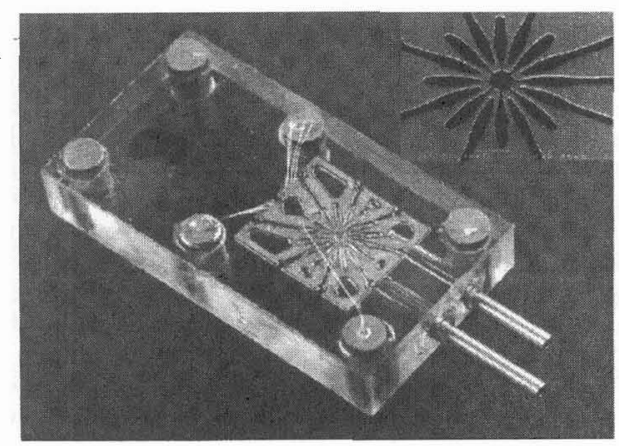

Figure 5: Microvalve without cover. The inset shows the active parts of the SMA device. 

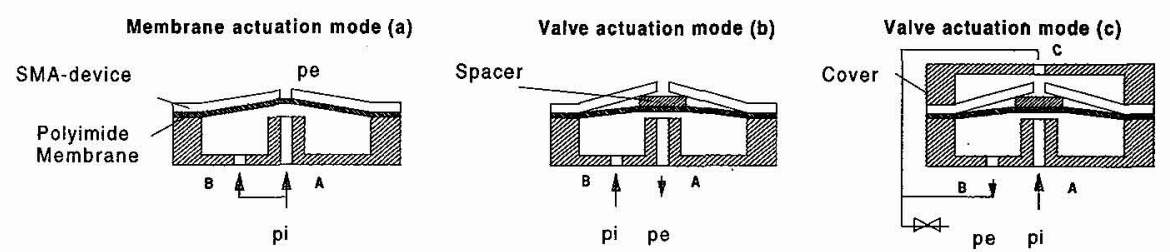

Figure 6: Different actuation modes of the valves. The applied pressure difference is pi-pe

\section{RESULTS AND DISCUSSION}

\subsection{Temperature distribution}

The temperature distribution along the surface of a SMA device has been investigated as function of electrical heating power by infrared microscopy. The measurements have been performed in thermal equilibrium. The infrared intensities have been calibrated by small thermocouples.

The temperatures increase linearly as a function of electrical heating power. Maximum temperatures occur at the beam ends and minimum temperatures at the beam roots. The temperature distribution is shown in Fig. 7 for $110 \mathrm{~mW}$ heating power. In this case, the whole actuator is heated above the finish temperature of the reverse transformation $(\mathrm{R} \rightarrow \mathrm{B} 2)$ of $44^{\circ} \mathrm{C}$. The maximum temperature at the beam end is $58^{\circ} \mathrm{C}$. For clarity, a scanning electron micrograph (SEM) of the investigated device area is shown in Fig. 8. For constant specific resistance, the temperature induced by electrical current is proportional to the crosssection of the beams. Even though the cross-section of the beams varies by a factor of 5.5 , the actuator temperature only varies by a factor of about 1.5. Thus, efficient thermal compensation takes place between regions of different cross-sections, which is governed by thermal conduction in the TiNi device and the PMMA substrate. The maximum possible electrical heating power was limited to about $450 \mathrm{~mW}$ by the thermal stability of the used adhesive. In this case, a maximum temperature of $170^{\circ} \mathrm{C}$ was observed. Below this power limit, no critical hot spots and sufficiently homogeneous temperature distributions occured.

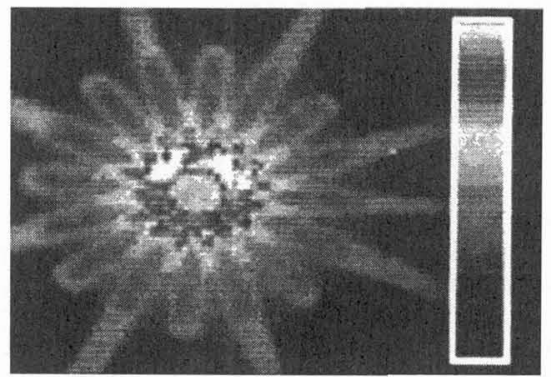

Figure 7: Temperature distribution of the top surface of the TiNi microdevice determined by infrared-microscopy. The heating power is $110 \mathrm{~mW}$. Maximum and minimum temperatures are $58^{\circ}$ and $44^{\circ} \mathrm{C}$, respectively.

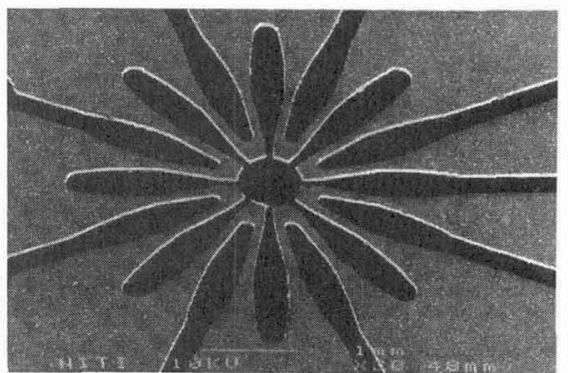

Figure 8: SEM showing the same region of the TiNi microdevice as shown in Fig. 7.

\subsection{Valve actuation in thermal equilibrium}

The advantages of stress-optimisation have been demonstrated by comparison of membrane actuators operated by a stress-optimised SMA device and.corresponding non-optimised devices with parallel beams, which revealed about a factor of 5 higher work output [12]. In the optimised actuator, a pure Rphase transformation was observed below $1200 \mathrm{hPa}$. The maximum strain was estimated to about $0.5 \%$, which corresponds to previous observations of maximum possible transformation strains in R-phase. [19] Above $1200 \mathrm{hPa}$, stress-induced martensite occured. In order to make use of a pure R-phase transformation the microvalves have therefore been designed for operation up to $1200 \mathrm{hPa}$. Thus, maximum stress and strain values are limited to about $60 \mathrm{MPa}$ and $0.12 \%$ in the austenitic phase, respectively, which has been calculated by an elastic beam-bending model using a Young's modulus of 53 GPa. These stress and strain values have to be considered as average values of RD and TD, which both contribute equally to the mechanical properties in this case due to the circular geometry.

In order to maintain a closed valve position below $1200 \mathrm{hPa}$, the SMA beams have been constraint by a spacer. The spacer thickness has been chosen to $60 \mu \mathrm{m}$, as measurements of membrane actuators revealed at $1200 \mathrm{hPa}$ a maximum beam displacement of $55 \mu \mathrm{m}$ in the austenitic phase. 


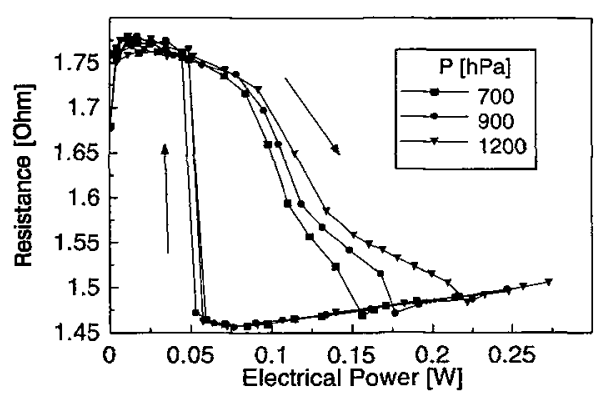

Figure 9: Resistance $v s$. electrical heating power for a microvalve operated in mode (b). $\mathrm{p}$ denotes the pressure difference.

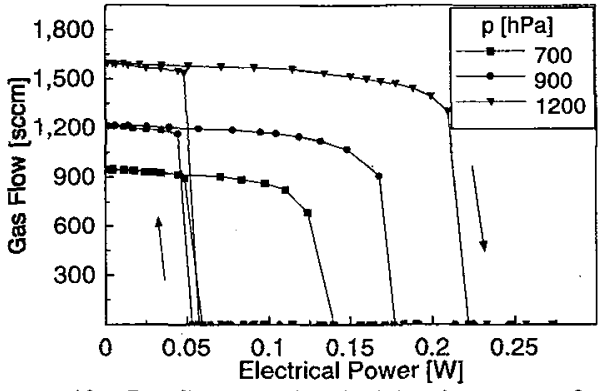

Figure 10: Gas flow vs. electrical heating power for a microvalve operated in mode (b). $p$ denotes the pressure difference.

Typical valve characteristics obtained in thermal equilibrium are shown in Figs. 9-11. Figs. 9 and 10 summarise the electrical resistance and gas flow characteristics as a function of electrical power for a valve operated in mode (b). At $1200 \mathrm{hPa}$, a maximum gas flow of $1600 \mathrm{sccm}$ is observed in open condition, where the SMA device is in R-phase. The corresponding maximum deflection of the membrane is $70 \mu \mathrm{m}$. From this value a maximum work output for closing the valve has been calculated to $35 \mu \mathrm{Nm}$. In closed condition, where the SMA microdevice is in austenitic phase, no leakage rate is detected. The critical power values for opening and closing the valve at $1200 \mathrm{hPa}$ are $55 \mathrm{~mW}$ and $210 \mathrm{~mW}$, respectively. In closed condition, only heat conduction contributes to cooling. Upon cooling, the power of conductive heat-loss $P$ cond becomes equal to the electrical heating power at $55 \mathrm{~mW}$. In open condition, both, conductive and pressure dependent convective cooling occurs. Therfore upon heating, Pcond and the power of convective heat-loss $P$ conv become equal to the electrical heating power at $210 \mathrm{~mW}$.

The wide hysteresis widths observed in Figs. 9-11 do not reflect the characteristic properties of R-phase transformation [19], but the pressure-dependent cooling rates of the SMA microdevice in open condition, which are governed by convection and conduction. Therefore, considerably higher electrical heating powers are required to close the valve compared to the minimum heating power to maintain a closed condition. This effect guarantees stable switching states. Investigations of microvalves with pressure compensation, operated in mode (c), revealed similar characteristics as shown in Figs. 9 and 10. However, this mode allows to control much higher pressure differences. So far $4500 \mathrm{hPa}$ have been achieved. Typical gas flow characteristics are shown in Fig. 11. Due to the fluidic resistor, the gas flows have been reduced to a maximum of about $400 \mathrm{sccm}$.

\subsection{Dynamic valve actuation}

The pressure-dependence of the response times for closing and opening the microvalves has been determined as a function of heating power. Fig. 12 shows typical results for a microvalve operated in mode (b). For closing the valve within a short time period, higher driving powers are required in dynamic measurements compared to thermal equilibrium conditions. The response times $t_{c}$ for closing the valves

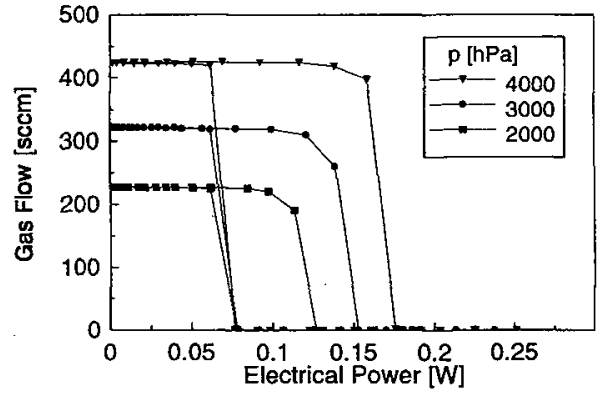

Figure 11: Gas flow vs. electrical heating power for a microvalve operated in mode $(c)$. p denotes the pressure difference.

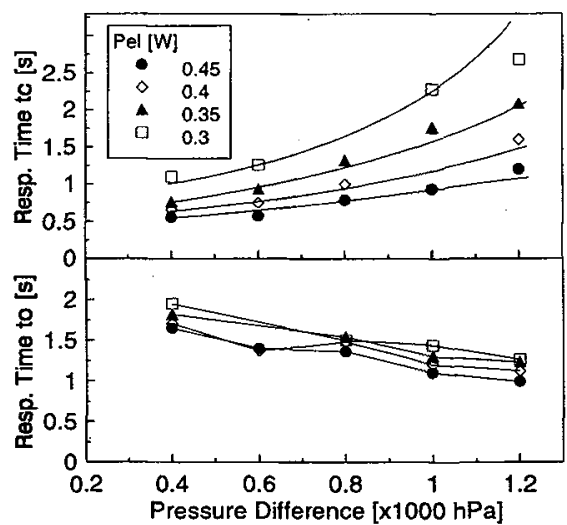

Figure 12: Response time for opening $t_{b}$ and closing $t_{c} v s$. pressure difference of a microvalve operated in mode (b). $\mathrm{Pel}$ denotes the electrical heating power. 
increase for increasing pressure due to a pressure-dependent increase of convective heat losses. For 1200 $\mathrm{hPa}$ and an electrical heating power of $450 \mathrm{~mW}$, a minimum response time of about $1.2 \mathrm{~s}$ is determined, for $400 \mathrm{hPa}$ this time reduces to about $0.5 \mathrm{~s}$. The time $t_{c}$ for closing the valve can be approximated by the following equation, which has e.g. been used previously to evaluate the heating times in SMA-wire actuators [20]:

$$
t c=\frac{m \cdot(c p \cdot \Delta T+Q t)+W}{P e l-P \operatorname{conv}-P \operatorname{cond}},
$$

where $m$ denotes the mass of the microdevice, $c p$ the thermal capacity, $\Delta T$ the temperature difference between room temperature and transformation temperature, $Q t$ the specific transformation energy, $W$ the work output and $\mathrm{Pel}$ the electrical heating. By eq. (3), closing times have been calculated, which are plotted as solid lines in Fig. 12. Pcond and Pconv have been approximated by the critical power values for opening and closing the valves, respectively, as determined from Figs. 10 and 11.

The response times $t_{o}$ for opening the valves are less affected by pressure, since convection only partially contributes to the cooling in this case. These times vary between 1 and $2 \mathrm{~s}$ for pressure differences between 400 and $1200 \mathrm{hPa}$.

\section{CONCLUSIONS}

Stress-optimised SMA microdevices with homogeneous stress distributions have been developed for deflection control of a membrane in gas microvalves. Specimens prepared by melting and final coldrolling with $20 \%$ reduction give rise to textures of [011] and [111] in rolling direction. The resulting anisotropy of transformation strains was investigated by tensile measurements revealing maximum recovery strains of $5 \%$ and $4.1 \%$ parallel and perpendicular to the rolling direction, respectively.

Investigations of temperature distributions on the surface of SMA microdevices performed by infrared microscopy revealed no hot spots and sufficient homogeneous temperature distributions in the power range below $450 \mathrm{~mW}$.

Valves with one pressure chamber have been designed for a maximum pressure difference of $1200 \mathrm{hPa}$, making use of a pure R-phase transformation. At this pressure limit a gas flow of $1600 \mathrm{sccm}$ and a work output of $35 \mu \mathrm{Nm}$ were observed. Valves with two pressure chambers for pressure compensation allowed operation at pressure differences up to $4500 \mathrm{hPa}$. In time-dependent investigations a strong dependence of heating times on the pressure difference was observed, which is mainly due to pressure-dependent convective cooling by the flowing gas. Typical response times for closing the valves vary between 0.5 and $1.2 \mathrm{~s}$, the times for opening between 1 and $2 \mathrm{~s}$.

\section{Acknowledgments}

The authors would like to thank H. Besser for laser cutting and W. Rapp for expert help in infrared microscopy.

\section{References}

[1] J.A. Walker, K.J. Gabriel, and M. Mehregany, Sensors and Actuators, A21-A23, (1990), pp.243-246.

[2] A.D. Johnson, J. Micromech. Microeng., 1,(1991), pp. 34-41.

[3] H.Holleck, S.Kirchner, E.Quandt et. al., Proc. Actuator 94, Bremen, FRG, (1994), pp. 361-364.

[4] S. Miyazaki and K. Nomura, Proc. MEMS 94 , Oiso, Japan, (1994), pp. 176-181.

[5] M. Kohl, E. Quandt, A. Schüßler, et.al., Proc. Actuator 94, Bremen, FRG, (1994) , pp. 317-320.

[6] T. Kim, Quanmin Su, and M. Wuttig, Mat. Res. Soc. Symp. Proc. Vol. 360, (1995), pp. 375-380.

[7] Li Hou, T.J. Pence, and D.S. Grummon, Mat. Res. Soc. Symp. Proc. Vol. 360, (1995), pp. 369-374.

[8] Y. Nakamura, S. Nakamura, L.Buchaillot, H.Fujita, Proc. MEMS 97, Nagoya, Japan, (1997), p. 262

[9] M. Kohl, K.D. Skrobanek, E. Quandt, et.al., Journal de Physique IV C8 (1995) pp. 1 187-1192.

[10] M. Kohl, K.D. Skrobanek, A. Schüßler, et.al., Proc. Actuator 96, Bremen, FRG, (1996) pp. 367-369.

[11] M. Kohl, K.D. Skrobanek, C.M. Goh, D.M. Allen, Proc. SPIE, Vol. 2880, (1996) pp. 108-118.

[12] K.D. Skrobanek, M. Kohl and S. Miyazaki, Proc. SPIE, Vol. 2779 (1996) pp. $499-504$.

[13] K.D. Skrobanek, M. Kohl and S. Miyazaki, Proc. MEMS 97, Nagoya, Japan, (1997), p. 256-261.

[14] M. Kohl, K.D. Skrobanek, S. Miyazaki, to be published at Transducers 97, Chicago, USA, (1997).

[15] K. Kitamura, S. Miyazaki, M. Kohl, Proc. Actuator 96, Bremen, FRG, (1996), pp.401-404.

[16] K. Kitamura, S. Miyazaki, H. Iwai and M. Kohl, Proc. SMST 97, California, USA, (1997).

[17] J.Van Humbeeck, D.Reynaerts, and R.Stalmans, Proc. Actuator 94, Bremen, FRG, p. 312, (1994).

[18] S. Miyazaki and K. Otsuka, Metall. Trans. A, Vol. 17A, (1986), pp. 53-63.

[19] S. Miyazaki, in Engineering aspects of shape memory alloys, edt. T.W. Duerig et al, Butterworth Heinemann Ltd, Great Britain, (1990), pp.394-413.

[20] P.A. Besselink, Proc. Actuator 96, Bremen (1996), FRG, pp.421-424. 